\title{
Structural Design and Optimization in the Beam of a Five-axis Gantry Machining Center
}

\author{
Xin Li ${ }^{1}$, Ying Huang ${ }^{2, *}$ and Zhi Zhou ${ }^{3}$ \\ ${ }^{1}$ College of Electrical and Mechanical Engineering, Agricultural University of Hebei, Baoding 071001, China \\ ${ }^{2}$ College of Information Engineering, Wuhan University of Engineering Science, Wuhan 430200, China \\ ${ }^{3}$ College of Land Resources, Agricultural University of Hebei, Baoding 071001, China
}

Received 14 November 2019; Accepted 31 January 2020

\begin{abstract}
Five-axis gantry machining centers are strategic equipment urgently needed for modern defense industry. These centers are also the basic manufacturing equipment for modern molds. Beams, which can affect the performance of the entire machine, are main components of the five-axis gantry machining center. This study proposed decision-making and optimizing methods for the beam design to improve the static and dynamic mechanical properties of beams and the quality and precision of processed products. Aiming at the multifactor and multilevel structure characteristics of beams, eight representative parameter combinations were established by orthogonal experiment as the design scheme of the beam structure. The software of finite element analysis was employed to analyze the static and dynamic characteristics of each beam and obtain their indicators. Meanwhile, a combined weighting method based on the entropy and fuzzy analytic hierarchy process was used to determine the weight value of each evaluation indicator. A fuzzy comprehensive evaluation method was applied to the multi-objective optimization of the beam structure design. Consequently, the parameter combination of the optimal scheme was finally determined to be "\#"-shaped stiffened panels with a thickness of $20 \mathrm{~mm}$ in the side-mounted lead rail. The sensitivity of key dimensions was analyzed, and six key dimensions were selected for optimization. Results show that D8 has the largest influence on the performance of crossbeams. After optimization, the total deformation, maximum equivalent stress, and mass of the beam are reduced by $3.207 \%, 13.619 \%$, and $2.457 \%$, respectively. Meanwhile, the first-order natural frequency is increased by $1.047 \%$. The present work improves the dynamic and static performances of beams and realizes a light-weight design. Moreover, this study shows strong engineering practicability and provides new ideas for the structural design and optimization of other key components in computerized numerical control (CNC) machining centers.
\end{abstract}

Keywords: Lower lateral force structure design of beam, Multi-objective selection, Finite element analysis, Sensitivity analysis, Size optimization

\section{Introduction}

With the rapid development of the national economy and the need for national defense, five-axis linkage gantry machining centers are currently facing an urgent market demand. These machining centers have high structural rigidity, large processing range, and high power. Among the modern metal cutting machine tools, five-axis linkage gantry machining centers have become advanced, completing complex surface processing and contour control. Therefore, the processed work piece can obtain high surface quality and machining precision. Beams, which connect key parts, such as rams and columns, are one of the key components of gantry machining centers. The static and dynamic mechanical properties of beams directly affect the quality and precision of work pieces. Therefore, designing a reasonable beam structure is important to improve the performance of machining centers and meet the requirements of static and dynamic performances of the beam to realize the lightweight design. For the machining center structure, the stressed structure model of beams is similar to the two-point simply-supported beam. Deformation is mainly attributed to gravity and cutting

\footnotetext{
*E-mail address: hybamboo@163.com

ISSN: 1791-2377 @ 2020 School of Science, IHU. All rights reserved.

doi:10.25103/jestr.131.11
}

reaction force during the machining process. The stable bending deformation caused by the beam gravity leads to wave deformation when the structural components (such as ram and head-stock) slide from one end to the other. In addition, the gravity of the beam produces a large eccentric effect and causes torsional deformation because the headstock and the ram are generally suspended on the beam [1]. The beam is subjected to cutting reaction forces during the machining process, which causes bending and torsion deformations and eventually reduces machining precision and work piece quality. Therefore, designing a reasonable beam structure is important to meet the requirements of static and dynamic performances of beams to improve the performance of machining centers. However, most computerized numerical control (CNC) machining centers still adopt traditional design methods. Based on experience, the classical mechanics method, which ignores the effect of dynamic factors, is used for the structural design and calculation and handles static problems multiplied by a safety factor. However, this method is single and inefficient. The precision of design results is poor due to the numerous assumptions and simplifications, thus leading to major defects or unreasonable conditions. Meanwhile, for security reasons, the safety factor is substantially high, resulting in a considerable amount of material waste [2-4]. With the development of computer aided design and computer aided 
engineering (CAD/CAE) technology, the manufacturing industry must move to a high level. Furthermore, additional scientific methods are necessary to guide the design of machining centers with complex structures.

Based on the above analysis, the technology of finite element static and dynamic analyses, virtual simulation technology, and improved fuzzy comprehensive evaluation method were used in this work to evaluate and optimize the beam structure design of five-axis gantry machining centers. Moreover, sensitivity analysis was used to optimize the key dimensions of optimal schemes. This method is generally applicable to improve the comprehensive performance of $\mathrm{CNC}$ machining centers and provide a theoretical basis and technical support for structural optimization.

\section{State of the art}

With the improvement of CAD/CAE technology, some manufacturing enterprises of $\mathrm{CNC}$ machining centers worldwide have recently adopted the paperless production mode, integrating CAD, CAE, computer aided manufacturing (CAM), and many other modules. Moreover, the emphasis of the design is gradually turned to digital development in a virtual environment instead of the physical environment for the experiment and simulation of working conditions. Scholars worldwide used the finite element software to simulate the machining center structure under different dynamic loads. For example, Aruna et al. [5] used the $\mathrm{CAD} / \mathrm{CAM}$ technology for parametric modeling and analysis of the five-axis machining center. Essid et al. [6] used the simulation technology to study the kinematic performance of $\mathrm{CNC}$ machine tools, thus driving the transformation of mechanical design from static to dynamic design [7]. Decision making regarding design schemes is necessary for the design of machining centers. Therefore, some scholars have explored the evaluation and optimization methods of design schemes. For example, Zatarain et al. [8] conducted the modal analysis of column mobile milling machines based on the finite element analysis and then determined the most reasonable structure by comparing several schemes. Tian et al. [9] established a threedimensional model with two types of stiffened plates. In their model, the minimum weight of the worktable was taken as the objective function to optimize the size. Moreover, the \#-type stiffened plate structure was selected after the finite element analysis of static and dynamic characteristics. However, the above study only considers a single performance indicator. Rao et al. [10] took the single objective function obtained by weighting the minimum flexibility and the maximum first-order natural frequency as the optimization objective. The optimum distribution of stiffeners was also obtained by optimizing the size of column structures. However, the weight of two subobjectives is not specifically analyzed; thus, this approach is not conducive to the design of machining centers.

Designers always aim for high low-order mode, large rigidity, and low mass in the design of machining centers. Thus, using multi-objective optimization [11] is necessary to meet the multiple performance indicators proposed by designers simultaneously. Therefore, based on the previous single-objective optimization methods, some Chinese scholars have utilized new algorithms and technologies for the multi-objective optimization of machining center designs

$\mathrm{Ju}$ et al. [12-14] compared four different beam structures of CNC machine tools and used the comprehensive scoring method to investigate the influence of each factor on each indicator. The best test protocol was then obtained by determining the optimal level considering the deformation, quality, and other factors. However, the evaluation method is subjective and inaccurate. Kumar et al. [15] applied the gray correlation analysis to the multi-working and multi-objective optimizations of machine tools without specific weight coefficients. Pang et al. [16] used the fuzzy comprehensive evaluation, technique for order preference by similarity to an ideal solution (TOPSIS), and gray relational analysis to examine various schemes of grinder beam structures and selected the optimal scheme based on three evaluation methods. The comparison shows that fuzzy comprehensive evaluation has the optimal effect, while TOPSIS has the worst. Liu et al. [17] established four optimization models of beam structures through finite element analysis of static and dynamic performance parameters. Finally, the optimal design scheme was determined by the analytic hierarchy process (AHP).

Although the indicator system determined by the AHP is relatively stable, the construction process of a comparison matrix is complicated and prone to judgment bias. The entropy method is a kind of objective valuation method with high objectivity and authenticity; this method is not influenced by subjective judgment. Therefore, the present study adopted AHP and entropy to determine the beam design scheme of machining centers.

The aforementioned study promoted the design and optimization theory of machining centers. Specifically, these works used modern design theory to select the optimal structure or identify dangerous points based on the virtual model analysis, thus improving the structure. However, the sensitivity of structural dynamic characteristics [18-21] is not analyzed, which leads to blindness and non-optimality of the optimization design. The research results are impracticable in engineering.

Thus, the present work adopted the combination weighting approach of entropy and AHP to determine the weight of evaluation indicators. The improved fuzzy comprehensive evaluation was used to optimize the beam design scheme of machining centers. Moreover, the sensitivity analysis technology was used to find the key design dimensions of beams and optimize the scheme, thus providing the design methods for the key components of machining centers.

The remainder of this study is organized as follows. Section 3 establishes the model of beam structures, obtains the evaluation indicators of static and dynamic characteristics through corresponding static and modal analyses of finite element, explores fuzzy evaluation method based on entropy method and AHP, and introduces the sensitivity analysis and optimization method of structural design. Section 4 categorizes the beam design scheme, determines the optimal scheme through the improved fuzzy comprehensive evaluation, selects the key dimensions affecting the performance of beams through sensitivity analysis technology, optimizes and modifies the key dimensions, and verifies the rationality of the optimization scheme. Section 5 summarizes the conclusions.

\section{Methodology}

\subsection{Orthogonal design of the beam}




\subsubsection{Design factors, levels, and evaluation indicators}

Based on the traditional design concept and practical application, the present work mainly considered the following factors to improve the structure design and beam.

(1) Structure and thickness of stiffened panels

Reasonable selection of the structure and thickness of stiffener panels is the basis of a lightweight design, which is beneficial to the static and dynamic performances of beams. Based on the bridge-type gantry beams commonly used by current machine tool plants, the present work selected 20 and $25 \mathrm{~mm}$ as the thickness of stiffener panels and four structures, namely, \#-type, X-type, O-type, and W-type (Fig. $1,2,3$, and 4, respectively). These complex structures improved beam stiffness and reduced stress deformation to obtain high machining precision despite the high processing technology requirement.

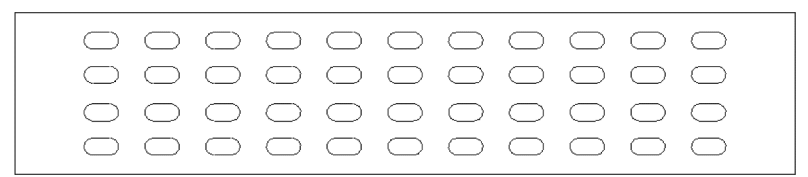

Fig. 1. \# type

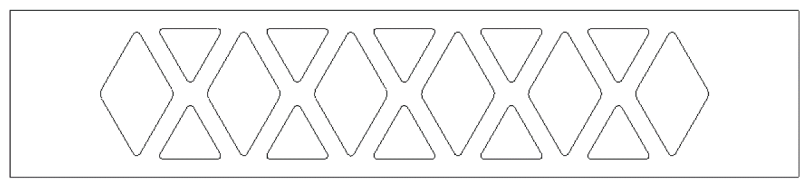

Fig. 2. $\mathrm{X}$ type

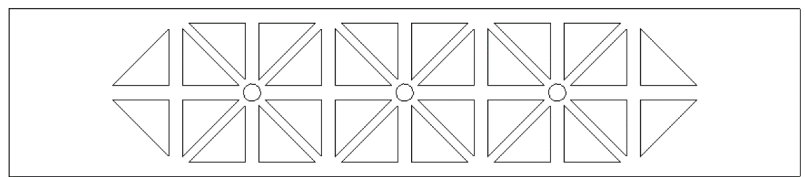

Fig. 3. O type

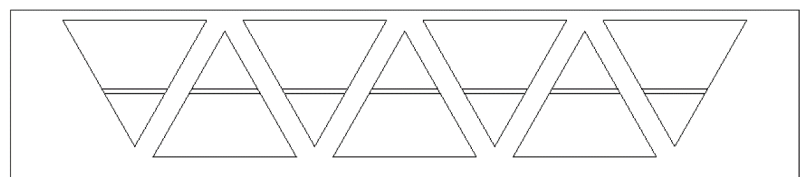

Fig. 4. W type

(2) Layout of guide rail

The guide rail position of the gantry machining center determined the application method of load on the beams, which included two forms. One form is a side-attached method, in which the assembly is mounted on the one-side guide rail of beams (Fig. 5a and b). Fig. 5a shows a simple section shape, and the guide rail is in the same plane. This form is convenient for simple processing in terms of technology. Hence, this form is widely used in the traditional machine tool structure. Fig. 5b shows a more complicated machining of guide rail than Fig. 5a. However, the bottom surface is larger than the top surface. Such a large surface improves the torsional stiffness. The other form is a symmetrical structure, in which the slider assembly is installed in the middle of the beam (Fig. $5 \mathrm{c}$ ). The guide rail is in the horizontal position of the top surface. Thus, the torsion deformation caused by the slide seat and headstock is relatively small. Fig. $5 \mathrm{~b}$ and $\mathrm{c}$ show the two layouts of beam rails. [22]

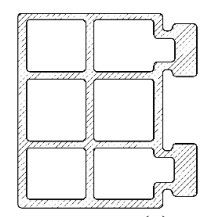

(a)

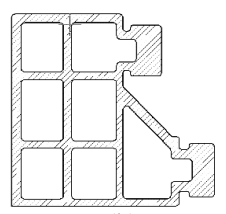

(b)

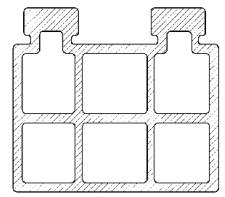

(c)
Fig. 5. Layout of guide rail

\subsubsection{Orthogonal experimental design}

Orthogonal experimental design [23-24] is a mathematicalstatistical method based on probability, statistics, empirical research, and engineering experience. According to orthogonality, the representative combination of factor parameters is selected to design the beam structure. Then, the orthogonal table is used to arrange the experimental plan under multifactor and multilevel conditions. Thus, the arrangement reduced the number of experiments and shortened the test period, thereby decreasing the difficulty in structural design and quickly identifying the optimization scheme. Taking the stiffener panel structure, beam thickness, and the layout and types of guide rails as the factors of orthogonal experiments, the present work designed a mixed horizontal orthogonal table with three factors (Table 1). The orthogonal design module in "SPSS statistics 20" is used to define the attribute variables and respective attribute levels, thus generating the orthogonal experiment schemes for eight kinds of beam structures (Table 2).

Table 1. Horizontal factors of designing the beam structure

\begin{tabular}{|c|c|c|c|}
\hline \multirow{2}{*}{$\begin{array}{c}\text { Horizonta } \\
\text { l }\end{array}$} & \multicolumn{3}{|l|}{ Factors } \\
\hline & $\begin{array}{l}\text { Structure of } \\
\text { stiffened panel }\end{array}$ & $\begin{array}{l}\text { Thickness of } \\
\text { stiffeners /mm }\end{array}$ & $\begin{array}{l}\text { Layout of } \\
\text { guide rail }\end{array}$ \\
\hline 1 & \#-type & 20 & Side-attached \\
\hline 2 & X-type & 25 & Symmetrical \\
\hline 3 & O -type & & \\
\hline 4 & W-type & & \\
\hline
\end{tabular}

Table 2. Orthogonal experimental design of the beam structure

\begin{tabular}{l|l|l|l}
\hline \multirow{2}{*}{ Scheme } & Factor level & & \\
\cline { 2 - 4 } & $\begin{array}{l}\text { Structure of } \\
\text { stiffened panel }\end{array}$ & $\begin{array}{l}\text { Thickness of } \\
\text { stiffeners } / \mathbf{m m}\end{array}$ & $\begin{array}{l}\text { Layout of guide } \\
\text { rail }\end{array}$ \\
\hline 1 & \#-type & 25 & Symmetrical \\
2 & X-type & 20 & Side-attached \\
3 & O-type & 20 & Symmetrical \\
4 & \#-type & 20 & Side-attached \\
5 & O-type & 25 & Side-attached \\
6 & X-type & 25 & Symmetrical \\
7 & W-type & 20 & Symmetrical \\
8 & W-type & 25 & Side-attached \\
\hline
\end{tabular}

\subsection{Finite element analysis of beam structures}

\subsubsection{Model of finite element analysis of beams}

According to the design scheme of the five-axis gantry, the beam was $4500 \times 1000 \times 1050 \mathrm{~mm}$. The present work used the "Pro/Engineer Wildfire 5.0" to establish the 3D parametric model of the orthogonal experiment schemes for each structure. Considering the computer hardware and the influence of model size on analysis precision and time consumption, the beam of a five-axis gantry machining center was simplified to improve the analysis. For example, some small bolt holes were neglected relative to the overall size, and then the structural guide rail was simplified without considering the contact and friction of the guide rail. 


\subsubsection{Static analysis of the beam}

The present work imported the simplified model into "ANSYS Workbench 19.0" for finite element analysis. The beam was molded by casting, and the main material was gray cast iron (HT300) with a density of $7.3 \times 103 \mathrm{~kg} / \mathrm{m}^{3}$, Young's modulus of $130 \mathrm{GPa}$, Poisson's ratio of 0.27 , and an ambient temperature of $22^{\circ} \mathrm{C}$.

A tetrahedral mesh based on the TGrid was used to divide the beam components of gantry machine tools. Considering the calculation precision and computer hardware, the unit size was set to $30 \mathrm{~mm}$. Moreover, the "relevance center" and the "span angle center" were respectively set to be "fine" and "medium." Then, the meshing results were obtained by the command of "Generate Mesh."

The research object of the present work is the fixedbeam gantry machining center. With the beam fixed on both sides of the upright columns, a fixed constraint is set on the connecting surface between the beam and column to limit all-degree freedom. As previously mentioned, weight and external excitation are the primary causes affecting beam deformation. The sliding ram, which is suspended on the beam, gradually twists and deforms under the influence of gravity. For large and heavy machine tools, all the components are large in weight; thus, the influence of gravity cannot be ignored in the course of structural analysis. The present work applied a vertical force of $2000 \mathrm{~N}$ to the middle of the beam, simulating the force as the sliding pillow moved to the middle. The force was applied to the top surface for symmetrical structures, while that for the sideattached structure was applied to the upper and lower rails.

The solver of "Static Structural," a type of static analysis module, was used to conduct analysis and obtain solutions. Thus, the total deformation, the deformations in $\mathrm{x}, \mathrm{y}$, and $\mathrm{z}$ directions, and equivalent stress and strain were acquired.

\subsubsection{Modal analysis of the beam}

The present work determined the stress distribution deformation through the static analysis of beams. However, during the working period of beams, the load changes with the cutting condition, resulting in an exciting force and even resonance. If the vibration amplitude caused by the exciting force exceeds the amplitude range required by machining precision, then this excess force would lead machining precision, unqualified work-piece surface, increased tool wear, and reduced processing efficiency. [1] Therefore, examining the dynamic characteristics of the beam is necessary.

Modal analysis is the basis of dynamic analysis, which is used to analyze the vibration characteristics of structures. The present work used modal analysis to determine the natural frequency and the corresponding vibration mode. Natural frequency is the characteristics of structures that are independent of the external load [25]. As the external-force frequency moves close to the natural frequency of objects, the amplitude gradually increases, resulting in a resonance phenomenon. Therefore, adjusting the structural design parameters is necessary. The common practice is to increase the low-order natural frequency, reduce the possibility of resonance, and improve the rigidity of the system, thus ensuring the stability and precision of the machining.

The processing of finite element modal analysis is the same as that of static analysis, except that modal analysis requires no load. After adding a fixed constraint bottom surface, the finite element modal analysis is found to be consistent with static analysis. The beam, which has an $\mathrm{N}$ - order mode, is an entity with continuously distributed mass and elasticity. However, the frequency of the external excitation force loaded on the beam is low in practice. Only the low-order natural frequency is close to or even the same as that of the external excitation, resulting in resonance phenomenon. The possibility of resonance and the impact on processing quality are small due to the large differences between high-order and external excitation frequencies. Therefore, setting a high order for modal analysis is unnecessary. The first several orders can generally meet the requirements.

The modal extraction order is set to 6 in the "Max Modes to Find." Next, the present work calculated and solved the first six-order natural frequencies and the corresponding mode diagram of the design schemes by clicking "Solve." Among the six-order natural frequencies, the first-order natural frequencies had the most reference value. Table 3 shows the analysis results of the static and dynamic characteristics of each design scheme.

Table 3. Simulation results of the static and dynamic performances of the beam

\begin{tabular}{|c|c|c|c|c|}
\hline \multirow[b]{2}{*}{$\begin{array}{l}\text { Sche } \\
\text { me }\end{array}$} & \multicolumn{4}{|c|}{ Simulation results } \\
\hline & $\begin{array}{l}\text { Volume } \\
\mathrm{U}_{1} / \mathrm{m}^{3}\end{array}$ & $\begin{array}{l}\text { Total } \\
\text { deformation } \\
\mathbf{U}_{2} / \mu \mathrm{m}\end{array}$ & $\begin{array}{l}\text { Maximum } \\
\text { equivalent } \\
\text { stress } \mathrm{U}_{3} / \mathrm{MPa}\end{array}$ & $\begin{array}{l}\text { First- } \\
\text { order } \\
\text { frequencie } \\
\text { s } \mathbf{U}_{4} / \mathbf{H z} \\
\end{array}$ \\
\hline 1 & 1.158 & 579.98 & 0.17664 & 32.858 \\
\hline 2 & 1.745 & 653.22 & 0.031182 & 99.713 \\
\hline 3 & 1.084 & 604.89 & 0.20247 & 29.61 \\
\hline 4 & 1.808 & 625.48 & 0.031319 & 100.2 \\
\hline 5 & 1.754 & 644.51 & 0.031876 & 99.733 \\
\hline 6 & 1.007 & 608.86 & 0.20328 & 30.19 \\
\hline 7 & 1.023 & 632.95 & 0.26871 & 26.766 \\
\hline 8 & 1.721 & 664.17 & 0.031935 & 100.57 \\
\hline
\end{tabular}

\subsection{Optimized method of schemes}

The meanings and functions of each evaluation indicator in the orthogonal test of beam structures are different, and the dimensions and orders of magnitude vary among indicators. Therefore, determining the pros and cons of each scheme only by visually analyzing the simulation of static and dynamic performances of beams is difficult. For the multiobjective optimization of beam-structure design, the improved method of a fuzzy comprehensive evaluation is used to process the simulation data.

\subsubsection{Determination of evaluation indicator weight}

The determination of evaluation indicator weight is a key part of the fuzzy comprehensive evaluation, and the accuracy of weighted value affects the optimization. The traditional methods of fuzzy comprehensive evaluation have strong subjectivity, and the optimized results occasionally have large deviations [26]. Thus, the present work used the combined weighting method based on entropy method and fuzzy AHP to ensure the objectivity of evaluated results and reduce the error impact of simulated data to determine the weight values of evaluation indicators.

(1) Calculation of weight by the entropy evaluation method

The entropy evaluation method is an objective weighting method used to calculate the information entropy of indicators. The weight of indicators is determined in accordance with the impact of the relative change of indicators on the system. An index with relatively large change has a large weight. Suppose $\mathrm{S}=\left\{\mathrm{S}_{1}, \mathrm{~S}_{2}, \cdots, \mathrm{S}_{\mathrm{n}}\right\}$ are $\mathrm{n}$ design schemes obtained by the 
orthogonal test of beam; $U=\left\{U_{1}, U_{2}, \cdots, U_{m}\right\}$ are $m$ evaluation indicators of the scheme; $a_{i j}$ is the simulation data of the $j$-th indicator in the $\mathrm{i}$-th scheme. The evaluation indicator matrix is established as follows:

$$
A=\left[a_{i j}\right]_{n \times m}=\left[\begin{array}{cccc}
a_{11} & a_{12} & \cdots & a_{1 m} \\
a_{21} & a_{22} & \cdots & a_{2 m} \\
\vdots & \vdots & & \vdots \\
a_{n 1} & a_{n 2} & \cdots & a_{n m}
\end{array}\right]
$$

A dimensionless method is applied to the evaluation indicator matrix A:

$a_{i j}^{\prime}=\frac{a_{i j}}{\sum_{i=1}^{n} a_{i j}}$

The weight matrix of the entropy evaluation method of evaluation indicator is $\mathrm{W}=\left[\begin{array}{llll}\mathrm{W}_{1} & \mathrm{~W}_{2} & \cdots & \mathrm{W}_{\mathrm{m}}\end{array}\right]$, where the weights of evaluation indicators are as follows:

$$
\begin{aligned}
& \mathrm{w}_{\mathrm{j}}=\frac{1-\mathrm{e}_{\mathrm{j}}}{\sum_{\mathrm{j}=1}^{\mathrm{m}}\left(1-\mathrm{e}_{\mathrm{j}}\right)} \\
& \mathrm{e}_{\mathrm{j}}=\frac{\mathrm{a}_{\mathrm{ij}}}{\sum_{\mathrm{i}=1}^{\mathrm{n}} \mathrm{a}_{\mathrm{ij}}}(\mathrm{j}=1,2, \cdots, \mathrm{m})
\end{aligned}
$$

(2) Weight calculation by fuzzy AHP

The AHP is a subjective valuation method that uses experts to measure the relative importance of indicators. Thus, selecting authoritative and representative experts who are familiar with the system of indicators is important. The fuzzy AHP is used to determine the priority among evaluation indicators. The 1-9 rating scale method is used as a judgment criterion to compare the indicators in pairs, with a weight judgment matrix established as follows:

$$
\mathrm{B}_{\mathrm{m}}=\left[\mathrm{b}_{\mathrm{ij}}\right]_{\mathrm{n} \times \mathrm{m}}=\left[\begin{array}{cccc}
1 & \mathrm{~b}_{12} & \cdots & \mathrm{b}_{1 \mathrm{~m}} \\
\frac{1}{\mathrm{~b}_{12}} & 1 & \cdots & \mathrm{b}_{2 \mathrm{~m}} \\
\vdots & \vdots & & \vdots \\
\frac{1}{b_{1 \mathrm{~m}}} & \frac{1}{b_{2 \mathrm{~m}}} & \cdots & 1
\end{array}\right]
$$

The weight matrix of fuzzy AHP for each evaluation indicator is $\mathrm{w}^{\prime}=\left[\begin{array}{llll}\mathrm{w}_{1}^{\prime} & \mathrm{w}_{2}^{\prime} & \cdots & \mathrm{w}_{\mathrm{m}}^{\prime}\end{array}\right]$, where the weights of each evaluation indicator are as follows:

$$
w_{i}^{\prime}=\frac{\sqrt[m]{\prod_{j=1}^{m} b_{i j}}}{\sum_{j=1}^{m} \sqrt[m]{\prod_{j=1}^{m} b_{i j}}}
$$

\section{(3) Combination weight}

The normalized method by multiplication is used to calculate the subjective and objective weights determined by the fuzzy AHP and entropy method. The weight of fuzzy comprehensive evaluation method is as follows:

$$
\begin{aligned}
& P=\left[\begin{array}{llll}
p_{1} & p_{2} & \cdots & p_{m}
\end{array}\right] \\
& p_{j}=\frac{w_{j} w_{j}^{\prime}}{\sum_{j=1}^{m} W_{j} w_{j}^{\prime}}(j=1,2, \cdots, m)
\end{aligned}
$$

\subsubsection{Determination of fuzzy comprehensive evaluation model}

For different evaluation indicators, some are the larger the better, such as the first-order natural frequency of beam. Some are the smaller the better, such as quality of beam, volume, maximum deformation, and maximum equivalent stress. The grade of the $\mathrm{j}$-th evaluation indicator for the $\mathrm{i}$-th beam scheme is recorded as $r_{i j}$. The quantification of $r_{i j}$ required its division into two types of evaluation indicator calculation:

$$
\left\{\begin{array}{l}
\frac{a_{i j}-\min _{1 \leq i \leq n} a_{i j}}{\max _{1 \leq i \leq n} a_{i j}-\min _{1 \leq i \leq n} a_{i j}}(j=1 \sim m, \text { the larger the better }) \\
\frac{\max _{1 \leq i \leq n} a_{i j}-a_{i j}}{\max _{1 \leq i \leq n} a_{i j}-\min _{1 \leq i \leq n} a_{i j}}(j=1 \sim m, \text { the smaller the better })
\end{array}\right.
$$

In this manner, the evaluation matrix of each evaluation indicator for the schemes is obtained as follows:

$$
\mathrm{R}=\left[\begin{array}{cccc}
\mathrm{r}_{11} & \mathrm{r}_{12} & \cdots & \mathrm{r}_{1 \mathrm{~m}} \\
\mathrm{r}_{21} & \mathrm{r}_{22} & \cdots & \mathrm{r}_{2 \mathrm{~m}} \\
\vdots & \vdots & & \vdots \\
\mathrm{r}_{\mathrm{n} 1} & \mathbf{r}_{\mathrm{n} 2} & \cdots & \mathrm{r}_{\mathrm{nm}}
\end{array}\right]^{\mathrm{T}}
$$

Using the weighted average algorithm, a fuzzy comprehensive evaluation model is also obtained:

$$
\mathrm{C}=\mathrm{P} \cdot \mathrm{R}=\left[\begin{array}{llll}
\mathrm{c}_{1} & \mathrm{c}_{2} & \cdots & \mathrm{c}_{\mathrm{n}}
\end{array}\right]
$$

$\mathrm{c}_{\mathrm{i}}=\sum_{\mathrm{j}=1}^{\mathrm{m}} \mathrm{p}_{\mathrm{j}} \mathrm{r}_{\mathrm{ij}}(\mathrm{i}=1 \sim \mathrm{n}, \mathrm{j}=1 \sim \mathrm{m})$

$c_{i}$ is the fuzzy evaluation result of the scheme of each beam and is sorted according to the numerical value to determine the preferred scheme.

\subsection{Sensitivity analysis}

Sensitivity analysis is a method used to study the sensitivity of system states to the changed system parameters. In structural design, this analysis refers to the sensitivity of performance functions of structural targets to changed design variables. Potential design parameters that can be modified are usually found in the optimized design scheme. The magnitudes of influences of different design parameters on the structural characteristics must be identified to select the optimized parameters. The basic principles are as follows: The mapping relation between objective function and design parameters is constructed mathematically. If the function of structure performance indicator $g$ to the design parameters $\mathrm{x}_{1}, \mathrm{x}_{2}, \cdots, \mathrm{x}_{\mathrm{n}}$ is $\mathrm{g}=\mathrm{F}\left(\begin{array}{llll}\mathrm{x}_{1} & \mathrm{x}_{2} & \cdots & \mathrm{x}_{\mathrm{n}}\end{array}\right)$, then the sensitivity of $g$ to $x_{i}$ is $S_{i}=\frac{\partial F(x)}{\partial x_{i}}$.

The magnitude of sensitivity Si reflects the influence of changed design parameters on the changed structural 
performance indicators. The values of sensitivity are sorted to select the design variables with a large impact on the dynamic performance of structures. Some minor design variables are reduced to improve optimization.

\section{Results analysis and discussion}

\subsection{Optimization of beam design}

The evaluation indicator matrix is established in Table 3. Using Equation (2), (3) and (4), the weight matrix of the entropy evaluation method of evaluation indicators was obtained as follows:

$\mathrm{W}=\left[\begin{array}{llll}0.109 & 0.271 & 0.293 & 0.327\end{array}\right]$
Six experts who have long been engaged in the development and production of five-axis gantry CNC machining centers were invited to compare the evaluation indicators in pairs using the 1-9 rating scale method and obtain a fuzzy judgment matrix. The weight of fuzzy AHP was calculated by Equation (6):

$$
\mathrm{w}^{\prime}=\left[\begin{array}{llll}
0.510 & 0.180 & 0.165 & 0.144
\end{array}\right]
$$

Equation (7) and (8) were used to obtain the combination weight:

$$
\mathrm{P}=\left[\begin{array}{llll}
0.278 & 0.244 & 0.242 & 0.236
\end{array}\right]
$$

Using the evaluation indicator matrix A, Equation (9) and (10), the evaluation matrix was obtained as follows:
$\mathrm{R}=\left[\begin{array}{llllllll}0.828 & 0.080 & 0.922 & 0.000 & 0.069 & 1.020 & 1.000 & 0.111 \\ 1.000 & 0.130 & 0.704 & 0.460 & 0.234 & 0.657 & 0.371 & 0.000 \\ 0.388 & 1.000 & 0.279 & 0.999 & 0.997 & 0.275 & 0.000 & 0.997 \\ 0.083 & 0.988 & 0.039 & 0.995 & 0.989 & 0.046 & 0.000 & 1.000\end{array}\right]$

The fuzzy evaluation matrix of the beam scheme was obtained using Equation (11) and (12):

$\mathrm{C}=\left[\begin{array}{llllllll}0.587 & 0.529 & 0.505 & 0.589 & 0.551 & 0.522 & 0.368 & 0.508\end{array}\right]$

Scheme 4 is the optimal design of the beam structure, with a \#-shaped reinforcing-plate structure with a thickness of $20 \mathrm{~mm}$. Meanwhile, the guide rail adopted a side-hanging layout. The model established in the experiment was simplified. Thus, Scheme 4 must be improved. A reinforcing plate was added longitudinally to increase beam stiffness. The beam structure was adjusted on the basis of manufacturing processes and load conditions. The improved model was analyzed for static and dynamic characteristics (Fig. 6 and 7, respectively). The optimized beam scheme was continued to improve the beam indicators.

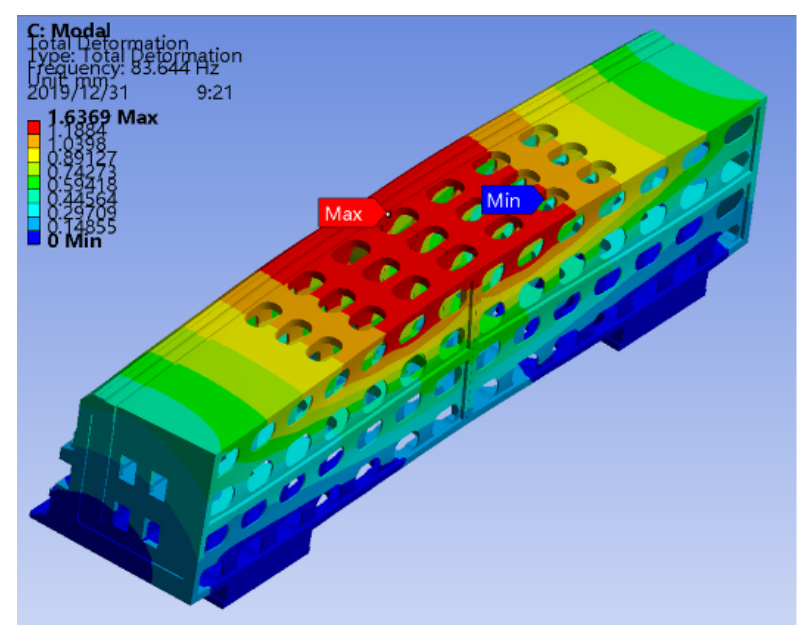

(a) Beam deformation

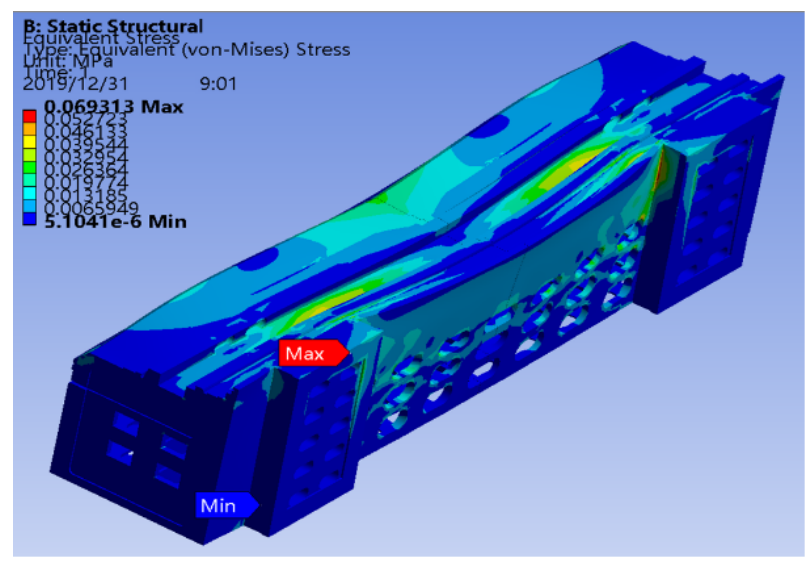

(b) Equivalent stress of beam

Fig. 6. Static and dynamic analyses of beam

4.2 Sensitivity analysis and key dimension optimization of optimized beam scheme

Ten important dimensions are selected in accordance with the structural characteristics of optimized beam scheme (Fig. 7).

The present work used the response surface optimization in the optimized module of ANSYS Workbench by setting the design type to be face-centered. The multi-objective functional relation was established by taking the 10 important dimensions selected as design variables and the volume, total deformation, maximum equivalent stress, and first-order natural frequency of beam as performance indicators. A 40-core workstation was used to calculate the sensitivity of key dimensions to the optimized target (Fig. 8). 


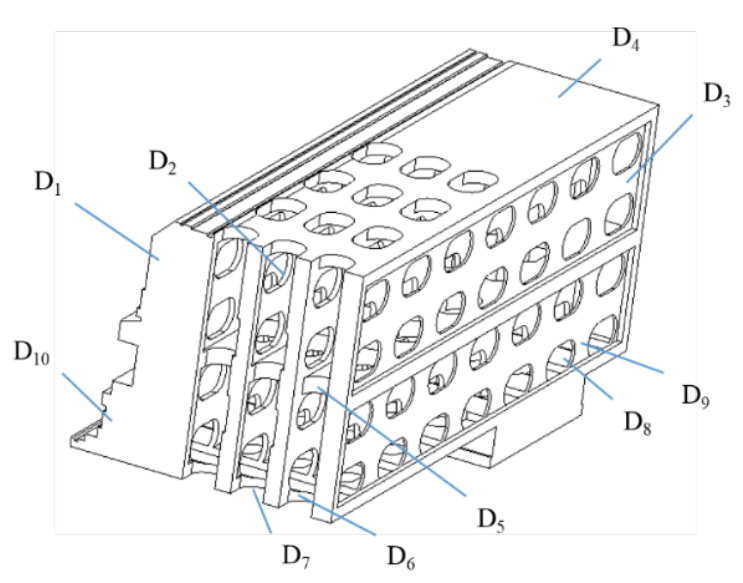

Fig. 7. Important beam dimensions

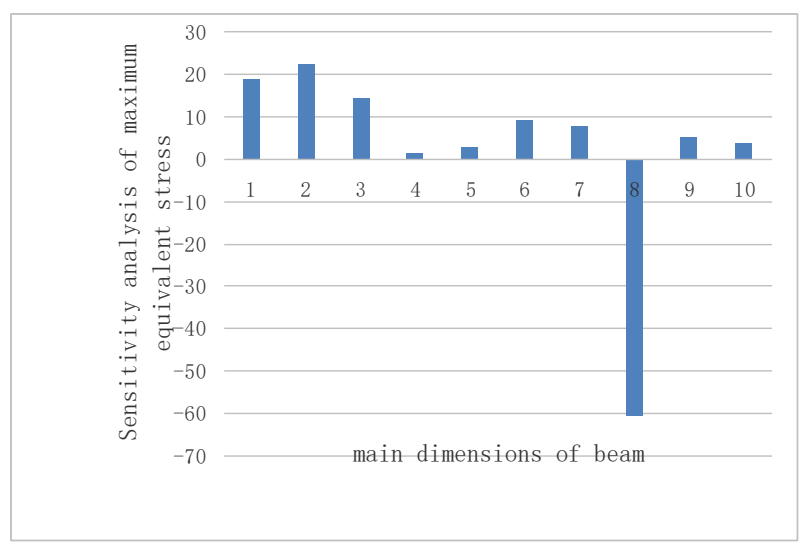

(a) Sensitivity analysis of maximum equivalent stress

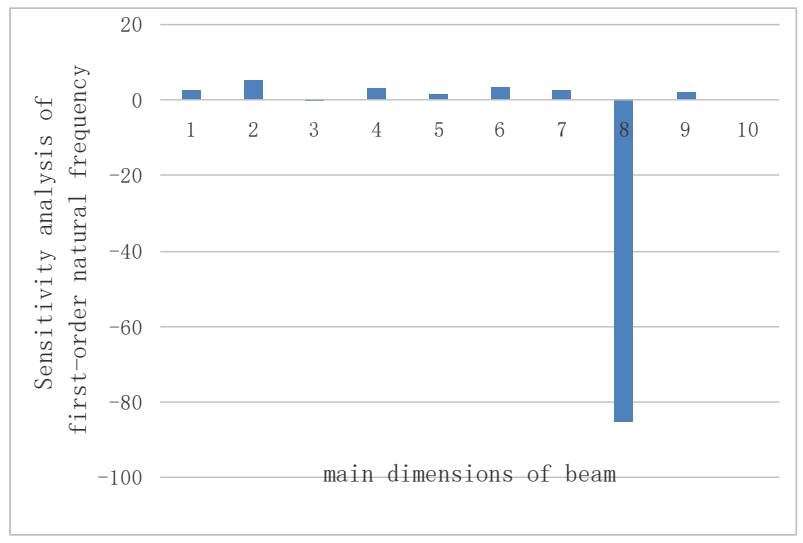

(b) Sensitivity analysis of first-order natural frequency

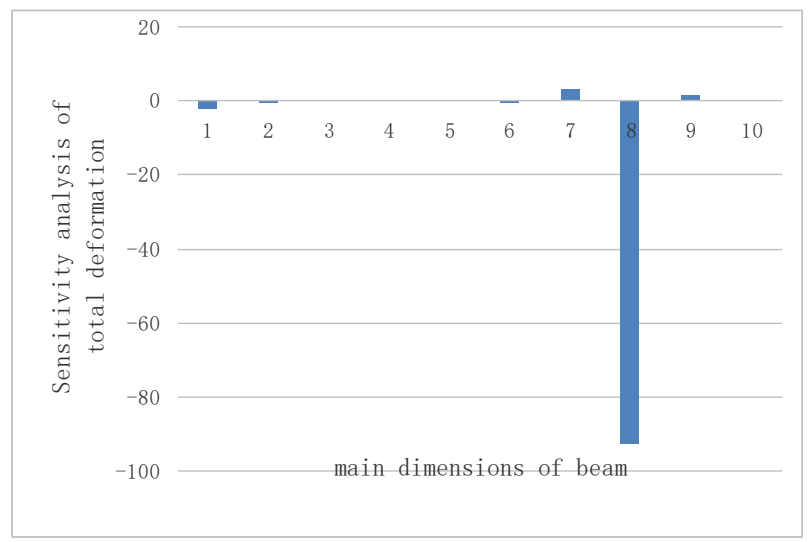

(c) Sensitivity analysis of total deformation

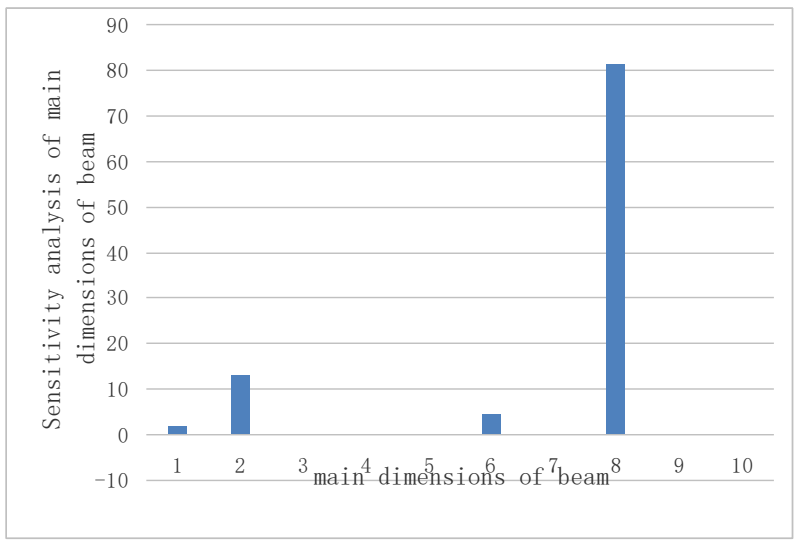

(d) Sensitivity analysis of volume

Fig. 8. Sensitivity analysis of main dimensions of beam

The results showed that $\mathrm{D}_{8}$ had the largest impact on performance indicators, positively related to volume. $\mathrm{D}_{4}$, $\mathrm{D}_{s}, \mathrm{D}_{9}$, and $\mathrm{D}_{10}$, which demonstrated low sensitivity to the performance indicators, could be ignored. $\mathrm{D}_{2}, \mathrm{D}_{3}, \mathrm{D}_{6}$, and $\mathrm{D}_{7}$ were more sensitive to the maximum equivalent stress and first-order natural frequency than the other dimensions. $\mathrm{D}_{7}$ was sensitive to the total deformation. $\mathrm{D}_{2}$ and $\mathrm{D}_{6}$ were sensitive to the volume. Nonetheless, all dimensions had positive correlations. The lower-limit value was appropriately reduced when the value range was set. $\mathrm{D}_{1}$, which was negatively correlated, had a remarkable sensitivity to total deformation. Meanwhile, the upper-limit value was appropriately increased when the value range was set. Therefore, $D_{1}, D_{2}, D_{3}, D_{6}, D_{7}$, and $D_{8}$ were selected as the key dimensions for optimization, with a total of 48 sample combinations.

Table 4. Key design dimensions of beams to be optimized and their value ranges (unit: $\mathrm{mm}$ )

\begin{tabular}{l|l|l|l}
\hline $\begin{array}{l}\text { Variable of key } \\
\text { dimension }\end{array}$ & Meaning & $\begin{array}{l}\text { Initial } \\
\text { value }\end{array}$ & Range \\
\hline $\mathrm{D}_{1}$ & $\begin{array}{l}\text { Thickness of front } \\
\text { wall } \\
\text { Thickness of front } \\
\text { reinforcing plate } \\
\mathrm{D}_{2}\end{array}$ & 219.95 & $200-245$ \\
$\mathrm{D}_{3}$ & $\begin{array}{l}\text { Thickness of back } \\
\text { wall } \\
\text { Thickness of upper } \\
\text { wall } \\
\text { Thickness of } \\
\mathrm{D}_{6}\end{array}$ & 10 & 45 \\
$\mathrm{D}_{7}$ & $\begin{array}{l}\text { horizontal } \\
\text { reinforcing plate } \\
\text { Thickness of lower } \\
\text { wall }\end{array}$ & 60 & $9-11$ \\
$\mathrm{D}_{8}$ & 32.5 & $40.5-49.5$ \\
\hline
\end{tabular}

The present work also set the optimized level of maximum equivalent stress of optimized target, total deformation, and first-order natural frequency as an important level and the volume as normal level. The optimal dimension was obtained after optimization. The optimal dimension was obtained by fitting the parameter values of multigroup samples. Hence, it was difficult to achieve the dimensional accuracy in production. The optimized dimensions were rounded up, and then the parameters were verified by substitution.

Table 5. Design dimension after rounding up (unit: $\mathrm{mm}$ )

\begin{tabular}{l|l|l}
\hline Variable of key dimension & Optimized value & $\begin{array}{l}\text { Actual } \\
\text { dimension }\end{array}$ \\
\hline$D_{1}$ & 203.14 & 203 \\
$D_{2}$ & 19.356 & 19
\end{tabular}




\begin{tabular}{l|l|l}
$\mathrm{D}_{3}$ & 9.9167 & 10 \\
$\mathrm{D}_{6}$ & 40.119 & 40 \\
$\mathrm{D}_{7}$ & 60.298 & 60 \\
$\mathrm{D}_{8}$ & 35.402 & 35 \\
\hline
\end{tabular}

\subsection{Static and dynamic characteristics of optimized beam scheme}

The model was updated in accordance with the optimized dimension, and the finite element analysis was conducted for verification. After dispersing, the numbers of divided units and nodes are 376,841 and 577,082, respectively. Moreover, the static and dynamic characteristics of the models before and after optimization were compared (Table 6).

Table 6 shows that after optimizing the key design dimensions, the total deformation, maximum equivalent stress, and mass of beams were reduced by $3.207 \%$, $13.619 \%$, and $2.457 \%$, respectively, while the first-order natural frequency was increased by $1.047 \%$. The dynamic and static performances of beams after optimization were also improved, thereby realizing a lightweight design. At present, the beams designed by this scheme have been utilized in a five-axis CNC machining center (Fig. 10).

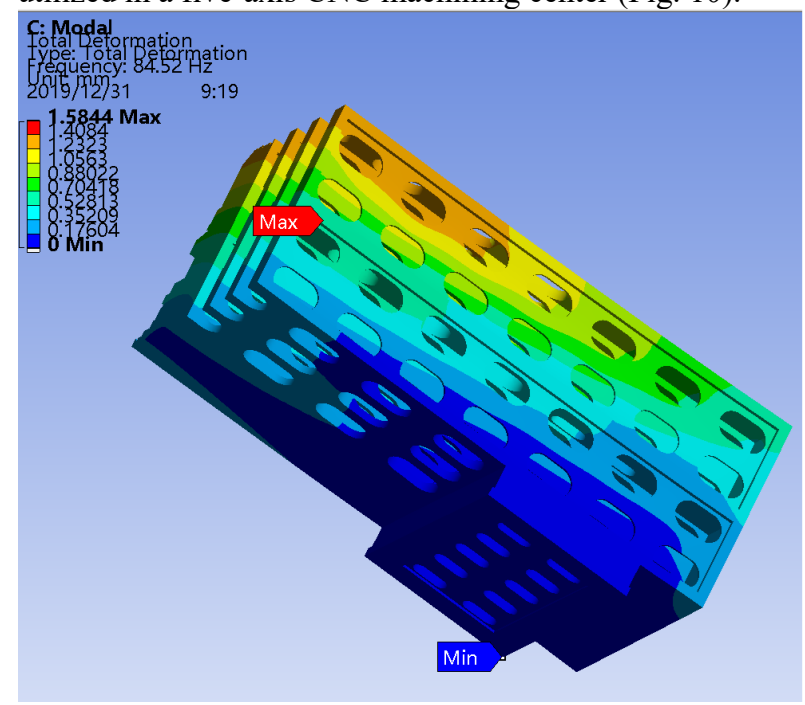

a)

\section{Conclusions}

Sensitivity analysis and dimension optimization method were applied to determine the optimal scheme of beam structure design. Moreover, these methods were employed to design a reasonable beam structure scheme, improve the static and dynamic performances of the beam, and realize lightweight design, orthogonal experiment method, entropy method, fuzzy AHP, and fuzzy comprehensive evaluation method. The scheme was also optimized. The following conclusions could be drawn.

(1) In the three-factor mixed-level scheme established by orthogonal experiments, the optimal beam structure

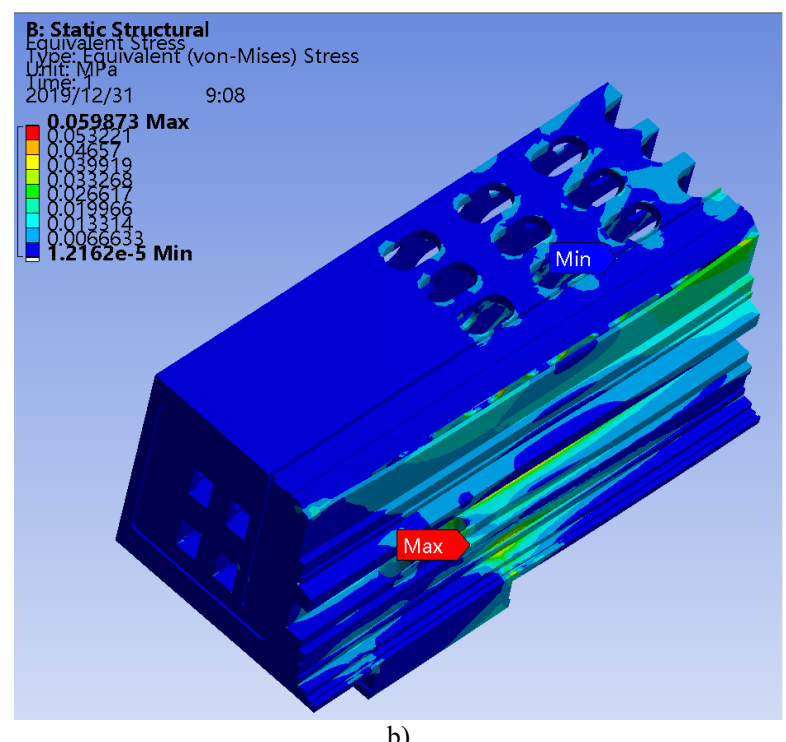

Fig. 9. Static and dynamic analysis of optimized beam (a) Total deformation of beam after optimization and (b) Equivalent stress of beam after optimization

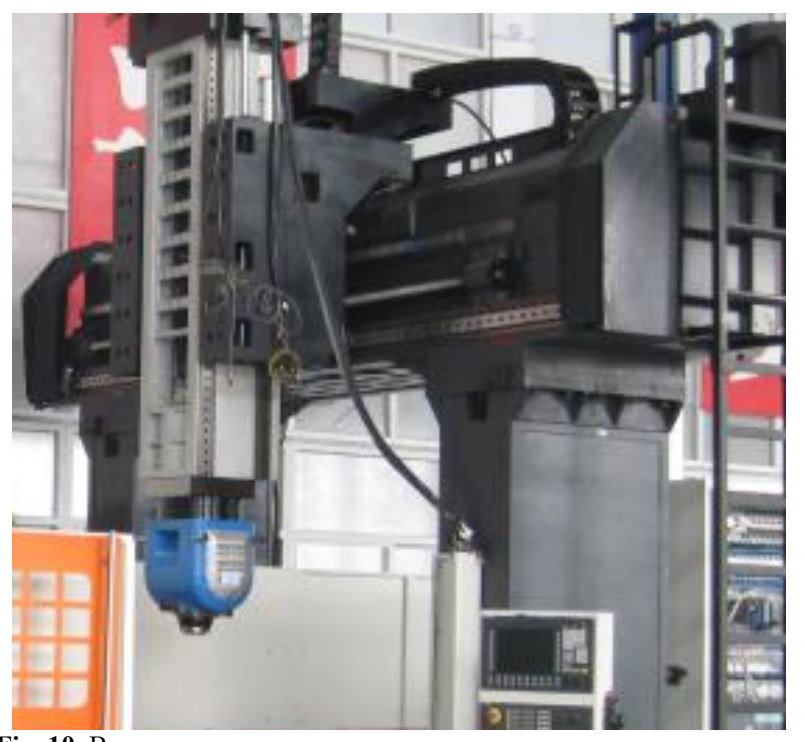

Fig. 10. Beam

Table 6. Comparison of static and dynamic performances of beams before and after dimension optimization

\begin{tabular}{l|l|l|l|l}
\hline Optimized target & Before optimization & After optimization & Variation \\
\hline Mass (kg) & 3776.7 & 3683.9 & -92.8 & $-2.46 \%$ \\
Total deformation & 1636.9 & 1584.4 & -52.5 & $-3.21 \%$ \\
Maximum equivalent stress & 0.069313 & 0.059873 & -0.00944 \\
First-order natural frequency & 83.644 & 84.52 & 0.876 & $-13.62 \%$ \\
\hline
\end{tabular}

by orthogonal experiments, the optimal beam structure

scheme is a "\#"-shaped reinforcing plate with a thickness of $20 \mathrm{~mm}$ in the layout of side-mounted rail.

(2) The key dimension $D_{8}$ has the largest influence on the performance indicator of beams. $D_{8}$ has a positive correlation with volume and a negative correlation with maximum equivalent stress, first-order natural frequency, and total deformation.

(3) After optimizing the key dimensions of beams, the quality, stress, and deformation are reduced, while stiffness and natural frequency are increased.

Thus, the research methods and design ideas presented in this work can help designers find the optimal design solution under multiple objectives, realize the lightweight design, and avoid the deformation and resonance of the main structure. The present study also has practical application value in 
improving the overall performance and design efficiency of the machining center. However, the beam component model is simplified appropriately without considering bolted connection, friction, guide rail contact, and influence of thermal field on the analysis. Thus, the results deviated from the actual situation. With the development of CAE technology, additional influencing factors can be considered simultaneously. This notion is consistent with the actual situation, and the results will be real.

\section{Acknowledgements}

This work was supported by the Science and Technology Support Plan Project of Baoding city (Grant No.1911ZG008) and the Education Department Scientific Research Project of Hubei Province (Grant No. B2018347)

This is an Open Access article distributed under the terms of the Creative Commons Attribution License

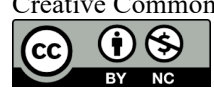

\section{References}

1. Lin, J., "Finite element static and dynamic characteristics analysis and structural design and optimization of gantry machine beams". Master thesis of Shaanxi University of Technology, China, 2016, pp. 30-31.

2. Zhang, Z. L., "Design of an automatic cutting machine for piston ring blank". Internal Combustion Engines and Accessories, 40(21), 2019, pp.84-85.

3. Zhou, X. X., Wang, W., Liu, W. P., Yin, Z. S., Sun, W., "Design and selection of chip conveyor and water tank for horizontal machining center machine tool". Mechanical Design, 37(S2), 2019, pp.143-146.

4. Liu, C. Sheng., Hsu, H. C., Lin, Y.X., "Design of a six-degree-offreedom geometric errors measurement system for a rotary axis of a machine tool". Optics and Lasers in Engineering, 127(4), 2020, pp.365-376.

5. Aruna, K. P., Prasad, B. S., "Machining of Steam Turbine Blade on five-Axis CNC Machine”. Materials Today: Proceedings, 18(7), 2019 pp.3001-3007.

6. Essid, M., Gassara, B., Baili. M., Hbaieb, M., Dessein, G., Saï, W. B., "Analytical modeling of the CNC machine axis motion in highspeed milling with local smoothing". The International Journal of Advanced Manufacturing Technology, 105 (1-4), 2019, pp.457-470.

7. Bal, B. C., Gündeş, Z., "Surface roughness of medium-density fiberboard processed with CNC machine". Measurement, 153(3), 2020, pp.218-226.

8. Zatarain, M., Lejardi, E., Egana F., "Modular synthesis of machine tools". Annals of the CIRP, 47 (1), 2018, pp.333-336.

9. Tian, Y. F., Wang, L. M., Li, Z. Y., "Design and analysis of ribbed plate of gantry $\mathrm{CNC}$ machine tool table based on topology optimization". Modular Machine Tool and Automatic Processing Technology, 57 (7), 2015, pp.57-60.

10. Rao, L.S., Hou, L., Pan, Y.J., Improvement of machine tool column reinforcement plate based on topology optimization". Mechanical Design and Research, 26 (1), 2010, pp.88-92.

11. Azhar M., Siddiqui, M. A., "Comprehensive exergy analysis and optimization of operating parameters for double effect parallel flow absorption refrigeration Cycle". Thermal Science and Engineering Progress, 16(5),2020, pp.1-8.

12. Ju, J. Q., Qiu, Z. X., Cui, D. Y., Ren, D., Shang. A. K., "Multiobjective optimization design of moving beam of machine tool based on orthogonal test". Mechanical Strength, 40 (2), 2018, pp.356-362.

13. Ju, J. Q., Qiu, Z. X., Ren, D., Liu, C. J., Liu, Z. H., "Design and research of machine tool column using grey theory and combined weighting method". Mechanical Science and Technology, 36 (9), 2017, pp.1388-1395.

14. Ju, J. Q., Liu, C. J., Cui, D. Y., Qiu, Z. X., "Optimal design of machine tool beam using grey correlation-analytic hierarchy process". Machinery Design and Manufacturing, 56(3), 2018, pp.26-29.
15. kumar, J., Soota, T., "Multi-response optimization of machining parameter for Zircaloy by response surface methodology and grey relation analysis". Materials Today: Proceedings, 27(11), 2019, pp.266-278.

16. Pang, J. P., Chen, Y. L., Liu, P., "Comparative Study on Optimum Design of Vertical Grinder Beam Structures_-Based on Fuzzy Comprehensive Evaluation Method, TOPSIS Method and Grey Correlation Analysis Method". Journal of Engineering Design, 20 (2), 2013, pp.89-96.

17. Liu S. H., Li, Y., Liao Y. L., "Structural optimization of the crossbeam of a gantry machine tool based on grey relational analysis". Structural \& Multidisciplinary Optimization, 50(2), 2014, pp.297-311. 18. Zhao, K. K., Tian, Y. F., Ye, X., "Study and optimization of layout of sliding guide rails for gantry machining center". Mechanical Science and Technology, 36 (9), 2017, pp.1388-1395.

19. Ménard, M. A., Quimper, C. G., "Jonathan Gaudreault. Preoptimizing tools positions for turrets-based $\mathrm{CNC}$ machines when facing arbitrary sequences of production". IFAC Papers On Line, 52(13), 2019, pp.1180-1185.

20. Yang, J. X., Altintas, Y., "A generalized on-line estimation and control of five-axis contouring errors of $\mathrm{CNC}$ machine tools". International Journal of Machine Tools and Manufacture, 88(11), 2015, pp.9-23.

21. Sonawane, H., Subramanian, T., "Improved Dynamic Characteristics for Machine Tools Structure Using Filler Materials". Procedia CIRP, 58(5), 2017, pp.399-404.

22. Gao, Z. L., Qiu, Z. X., Ren, D., Cui, D. Y., Xu, X. P., "Structural design and optimization of beam of bridge type gantry milling machine". Journal of Engineering Design, 26 (1), 2019, pp.56-64.

23. Yuan, J., Zhou, C. Y., Shen, Y. F., "Research on test conditions of radial runout of spindle based on orthogonal design". Combined Machine Tool and Automatic Processing Technology, 59(3), 2017, pp. 21-23, 27.

24. Mao, H. J., Shu M., Li, C., "Optimization design for beam structures of rail weld CNC fine milling machine based on ANSYS Workbench". Applied Mechanics \& Materials, 716-717(4), 2015, pp.817-824.

25. Cao, M., "Study on the static and dynamic characteristics of the beam components of large-scale CNC gantry machine tools". Doctoral Dissertation of Shaanxi University of Technology, China, 2015, pp.34-35.

26. Xia, H. M., Zhen, W. B., Zeng, W., "Fuzzy comprehensive evaluation of the configuration scheme of fruit and vegetable picking mechanism". Mechanical Science and Technology, 33 (2), 2014, pp. $178-182$. 